\title{
The Docosanoid Neuroprotectin D1 Induces TH-Positive Neuronal Survival in a Cellular Model of Parkinson's Disease
}

\author{
Jorgelina M. Calandria ${ }^{1} \cdot$ Michelle W. Sharp $^{1} \cdot$ Nicolas G. Bazan $^{1}$
}

Received: 6 March 2015/Accepted: 5 May 2015/Published online: 6 June 2015

(c) The Author(s) 2015. This article is published with open access at Springerlink.com

\begin{abstract}
Parkinson's disease (PD) does not manifest clinically until $80 \%$ of striatal dopamine is reduced, thus most neuronal damage takes place before the patient presents clinical symptoms. Therefore, it is important to develop preventive strategies for this disease. In the experimental models of PD, 1-methyl-4-phenylpyridinium ion (MPP+) and rotenone induce toxicity in dopaminergic neurons. Neuroprotectin D1 (NPD1) displays neuroprotection in cells undergoing proteotoxic and oxidative stress. In the present report, we established an in vitro model using a primary neuronal culture from mesencephalic embryonic mouse tissue in which $17-20 \%$ of neurons were TH-positive when differentiated in vitro. NPD1 $(100 \mathrm{nM})$ rescued cells from apoptosis induced by MPP+ and rotenone, and the dendritic arbor of surviving neurons was examined using Sholl analysis. Rotenone, as well as MPP+ and its precursor 1-methyl-4-phenyl-1,2,3,6tetrahydropyridine (MPTP), severely promoted retraction of dendritic arbor distal segments, thus decreasing the maximum branch order reached. On average, NPD1 counteracted the effects of MPP+ on the dendritic arborization, but failed to do so in the rotenone-treated neurons. However, rotenone did decrease the Sholl intersection number from radii 25 to $125 \mu \mathrm{m}$, and NPD1 did restore the pattern to control levels. Similarly, NPD1
\end{abstract}

Electronic supplementary material The online version of this article (doi:10.1007/s10571-015-0206-6) contains supplementary material, which is available to authorized users.

Nicolas G. Bazan

nbazan@1suhsc.edu

1 Neuroscience Center of Excellence, School of Medicine, Louisiana State University Health Sciences Center, 2020 Gravier Street, Suite D, New Orleans, LA 70112, USA partially reverted the dendrite retraction caused by MPP+ and MPTP. These results suggest that the apoptosis occurring in mesencephalic TH-positive neurons is not a direct consequence of mitochondrial dysfunction alone and that NPD1 signaling may be counteracting this damage. These findings lay the groundwork for the use of the in vitro model developed for future studies and for the search of specific molecular events that NPD1 targets to prevent early neurodegeneration in PD.

Keywords Neuroprotectin D1 - TH-positive neurons · Parkinson's disease $\cdot$ Neuroprotection $\cdot$ MPP+

\section{Introduction}

Parkinson's disease (PD) does not manifest clinically until $80 \%$ of the striatal dopamine has been lost (Betarbet et al. 2002). Therefore, it is vital to develop strategies that prevent the loss of dopamine neurons.

Until recently, the significance of the selective enrichment of omega-3 essential fatty acids (docosahexaenoylDHA - chains of membrane phospholipids, 22C and 6 double bonds) in the nervous system had remained incompletely understood (Bazan et al. 2011; Bazan 2014). We now know that an integral membrane protein is engaged in DHA retention in photoreceptors/retinal pigment epithelial cells as a necessary event for the function of these cells (Rice et al. 2015). By studying early mechanisms of cell survival, we found that a docosanoid synthesized from docosahexaenoic acid (DHA) by 15-lipoxygenase-1 (15-LOX-1), neuroprotectin D1 (NPD1; 10R,17S-dihydroxy-docosa-4Z,7Z,11E,13 $E, 15 E, 19 Z$ hexaenoic acid) (Bazan et al. 2010; Calandria 
et al. 2009; Serhan et al. 2015), displays neuroprotective bioactivity. Moreover, NPD1 prevents apoptosis induced by oxidative stress (Calandria et al. 2009, 2012) involving transcriptional regulation (Calandria et al. 2015). Previously, it has been shown in experimental models of PD that MPP+ and rotenone inhibit the Complex I of the mitochondrial electron chain and causes specific toxicity to dopaminergic neurons in the substantia nigra pars compacta (SNpc) (Betarbet et al. 2000; Davis et al. 1979; Langston et al. 1983; Richardson et al. 2005).

The goal of this study was to develop an in vitro model of PD where lipid mediators could be studied in a direct manner and to determine the ability of NPD1 to enhance survival during early toxicity in mesencephalic TH-positive neurons. We used a onetime application of 1-methyl-4phenylpyridinium ion (MPP+), 1-methyl-4-phenyl-1,2,3,6tetrahydropyridine (MPTP), or rotenone, measuring survival and dendritic architecture modification in the remaining neurons after $24 \mathrm{~h}$. In this manner, we established a cellular model to reenact the first toxic event that dopaminergic cells undergo as an early response in neurodegeneration.

\section{Materials and Methods}

\section{Animals and Reagents}

Animals were handled following protocols on animal experimentation approved by the Institutional Animal Care and Use Committee (IACUC), Louisiana State University Health Sciences Center (LSUHSC), New Orleans. Culture media, additives and other related reagents, including trypsin and B-27/N2, were purchased from Life Technologies (Carlsbad, CA). Fetal bovine serum (FBS) was acquired from Tissue Culture Biologicals (Long Beach, CA), and glial cell line-derived neurotrophic factor (GDNF) and transforming growth factor beta (TGF- $\beta$ ) were from Cell Sciences (Canton, MA). DNAseI, dbcAMP, MPTP, MPP+ and rotenone were obtained from Sigma (St. Louis, MO). Anti-tyrosine hydroxylase antibody was purchased from Pel-Freez (Rogers, AR); anti- $\beta$-tubulin III was from Sigma (St. Louis, MO) and anti-Map2 from Millipore (Billerica, MA). Secondary antibodies conjugated with Alexa Fluor 488 and 555 and nuclei staining DAPI were obtained from Life Technologies (Carlsbad, CA).

\section{Rat Mesencephalic TH-Positive Neurons: Primary Culture, Treatment, and Immunocytochemistry}

The cultures were performed following the methods described previously (Sun et al. 2004) with some modifications. Briefly, $1 \mathrm{~mm}^{3}$ of the ventricular mesencephalic region was obtained from Sprague-Dawley rat embryos (embryonic day 15). Two incisions were made, one in the forebrain/mesencephalic limit and the other between the mesencephalon and the hindbrain. Once dissected from the meninges, the tissue was disaggregated using trypsin and DNaseI. Twenty thousand cells were plated in each well of an 8-well chamber slide with B-27/ $\mathrm{N} 2$ medium containing $2.5 \%$ serum. GDNF, TGF- $\beta$, and dcAMP were added once to increase TH-positive cells (Supplementary Fig. 1) and the media were changed every 2 days. The percentage of TH-positive cells achieved was 17-20\%. NPD1 (100 nM) was added to the culture at 7 DIV, $5 \mathrm{~min}$ before the addition of $100 \mathrm{nM}$ rotenone, $100 \mu \mathrm{M}$ MPP+ or $100 \mu \mathrm{M}$ MPTP. To decide the time of exposure to MPTP and rotenone, 24- and 48-h time points were used (Supplementary Figs. 2, 3). Immunostaining was performed following a previously described protocol $(\mathrm{Ca}-$ landria et al. 2012). Briefly, cells were fixed with $4 \%$ paraformaldehyde, permeabilized with $1 \%$ Triton and $1 \%$ normal serum in phosphate buffered saline (PBS) for $5 \mathrm{~min}$, and then blocked with $10 \%$ normal serum solution in PBS. The slides were incubated with the primary antibody overnight and then for $1 \mathrm{~h}$ with Alexa fluor-conjugated secondary antibodies.

\section{Image Acquisition, Assessment of the Dendritic Arbor, and Statistics}

Images were obtained using a custom-built deconvolution microscope and Slidebook 4.0 software (3i-Intelligent Imaging Innovations, Inc., Denver, CO). Images were imported and analyzed using the software Imaris 7.4 (Bitplane Scientific Software, Ireland, UK) or NeuronJ (Meijering et al. 2004) plugged into ImageJ (Rasband 19972014). The intersection frequencies of Sholl analysis were plotted and analyzed statistically to fit a polynomial regression to assess the statistically significant differences between treatments within an experiment (Supplementary Table 1; Fig. 2q). The Sholl values were used to construct a frequency histogram and compared between treatments within each class interval and between intervals using Student's $t$ test (Tables 1,2). The statistical analysis was performed using the SAS software (SAS Institute, Cary, NC).

\section{Results}

\section{TH-Positive Neuron Cell Death Triggered by Rotenone and MPP + is Prevented by NPD1}

Rotenone and the MPTP metabolite, MPP+, was proposed to induce toxicity primarily by blocking mitochondrial 
Complex I, which results in the production of superoxide radicals and consequently, oxidative stress (Ramachandiran et al. 2007). To determine the ability of NPD1 to prevent cell death induced by these three compounds, mesencephalic primary-cultured neurons were exposed to $100 \mathrm{nM}$ rotenone, $100 \mu \mathrm{M}$ MPTP, or $100 \mu \mathrm{M} \mathrm{MPP}+$ in the presence and absence of NPD1 for $24 \mathrm{~h}$ (Fig. 1a-c). MPP+ severely decreased the number of TH-positive neurons from $40.3 \pm 7.3$ in the control to $7.6 \pm 1.6$; with the addition of NPD1, the number of surviving cells was raised to $14.4 \pm 2.7$ (Fig. 1b). MPTP, the precursor of MPP+, also displayed toxicity, promoting the disappearance of $65.7 \%$ of the TH-positive neurons, but this effect was not significantly counteracted by NPD1 (Fig. 1b). On the other hand, rotenone reduced the TH-positive neuronal population $63 \%$, and NPD1 reversed that effect almost completely (Fig. 1c). The NPD1 stereoisomer (10S,17SdiHDHA) had no effect on TH-positive cell survival, indicating that the protection was specifically induced by the $S / R$ stereoisomer (Figs. 1c, 2o, p).

\section{Neurons That Survived with the Addition of NPD1 Showed Better Dendritic Morphology on Average}

Mitochondrial damage and depletion leads to neurite retraction or shortening (Cherra et al. 2013). We analyzed the dendritic arbors of surviving TH-positive neurons to evaluate whether NPD1 addition affected neurite integrity. General features were assessed, including maximum dendritic order reached for each TH-positive neuron, number of dendrite segments and branches, the sum of all the segment lengths for each neuron, and the mean for the dendrite diameters. MPTP and MPP+ only altered the parameters related to the length of the dendrites and not related to their thickness, as shown in Fig. 1d-m. Overall, the integrity of the dendritic arbor was best preserved in cells treated with NPD1 in comparison with the ones that survived without NPD1 treatment (Fig. 1d-m). Although more TH-positive neurons survived the rotenone treatment with the addition of NPD1 (Fig. 1c), there was no difference in the maximum dendritic order, the number of segments, or the combined length of all branches and segments when neurons were treated with the lipid mediator (Fig. 1n, o, q). Intriguingly, the number of branches (Fig. 1p) on average did not show any significant changes in rotenone-treated $\mathrm{TH}$-positive neurons when compared to controls, suggesting a different mechanism of toxicity. On the contrary, MPP+ induced a reduction in length and number of branches (Fig. 1d, f, h, j, 1), and these effects were reversed almost completely by NPD1. MPTP produced an outcome similar to MPP+, although NPD1 did not provide the same level of improvement (Fig. 1e, g, i, k, m).

\section{D Analysis of Dendritic Branching shows that NPD1 prevents Neurite Retraction at Short to Medium Radii}

The Sholl number is the frequency by which neurites intersect in concentric circles drawn around the soma at different radii (Fig. 2b). To further visualize spatially the alterations introduced by MPP + and its precursor MPTP or rotenone, the total number of Sholl intersections per treatment were averaged and plotted versus the radius (Fig. 2a, e, i). Two-way ANOVA showed significant differences between treatments (Supplementary Tables 2, 3). The Sholl values were fit to a polynomial curve using the least squares model (Supplementary Table 1; Fig. 2q). To assess the distances from the soma at which the differences occurred in the dendritic tree, the curves were broken down into six class intervals containing radii from 0 to 25,26 to 50, 51 to 75,76 to 100,101 to 125 , and 126 to $150 \mu \mathrm{m}$ (Tables 1,2). Pairwise comparisons between treatments in each interval showed that MPP+ induced a consistent and significant decrease in neurites at all radii and that this effect was totally reversed by NPD1 within the interval from 0 to $25 \mu \mathrm{m}$ and partially from radius $26 \mu \mathrm{m}$ or over (Table 1). MPP+- and MPTP-treated neurons showed significant differences, in the presence and absence of NPD1, for radii $0-125 \mu \mathrm{m}$ (Table 1; Fig. 2a, e). On the other hand, NPD1 stereo-specifically reversed rotenoneinduced reduction in the Sholl number at radii 25-100 $\mu \mathrm{m}$ (Fig. 2i; Table 2). Altogether, these results suggest that $\mathrm{MPP}+$ and rotenone exert their toxicity through different mechanisms and that NPD1 halts damage caused by rotenone and MPP + to TH-positive neurons.

\section{Terminal Neurites are protected from MPP+ Toxicity by NPD1}

Total and terminal number of dendrites were plotted versus the dendritic order to assess the location of damage within the dendritic tree. On average, the total dendritic segments were decreased from $24.9 \pm 2$ in the control to $8.1 \pm 1$ in neurons treated with MPP+ (Fig. 3a), and the average terminal number of segments followed the same trend (Fig. 3c). The vehicle control DMSO showed a reduction of about $30 \%$ in total segments (Fig. 3a). The number of total and terminal segments started to decline at the dendritic order 2 for the MPP+-treated neurons, and the greatest difference in numbers was reached at dendritic order 3. NPD1 was more effective in protecting dendritic segments at order 2. Following that order, even in the presence of NPD1, the number of total segments was reduced significantly in comparison with the control (Fig. 3b). Terminal branches behaved in a different way. In 
A

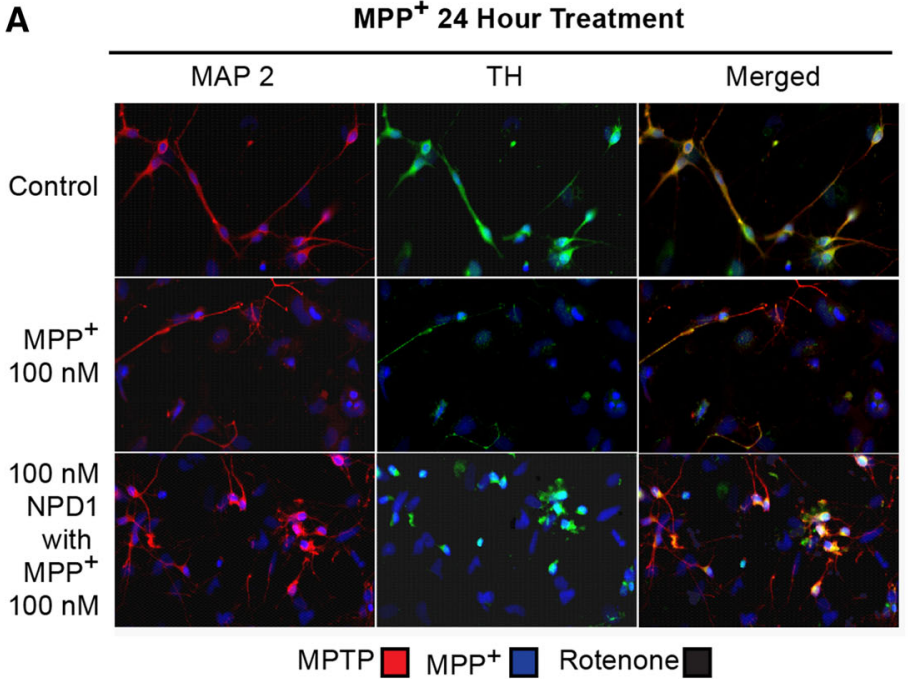

$\mathbf{F}$

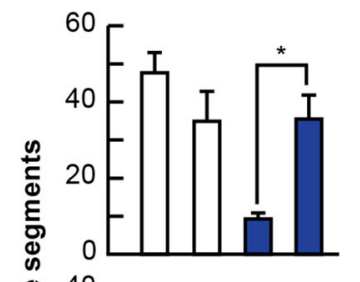

G

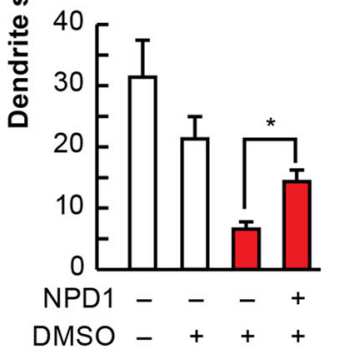

H

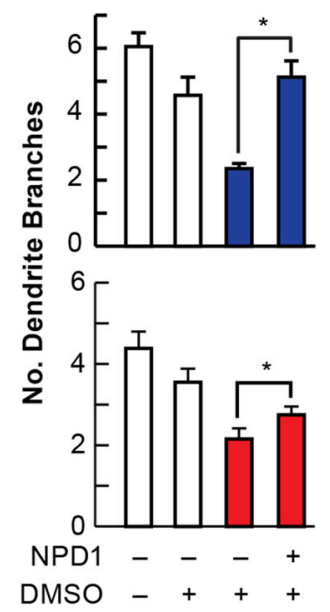

B

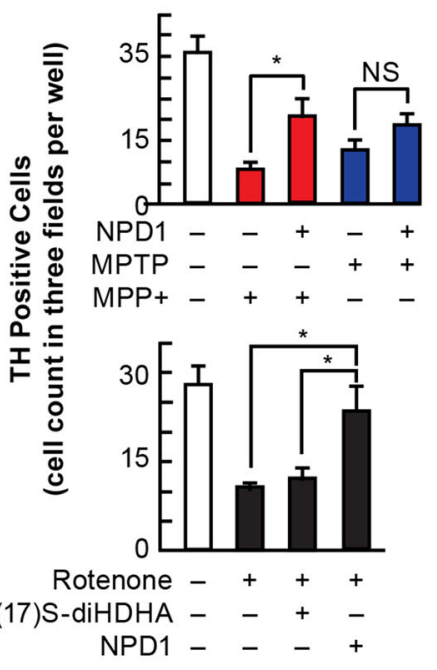

D $60^{2}$ J

E

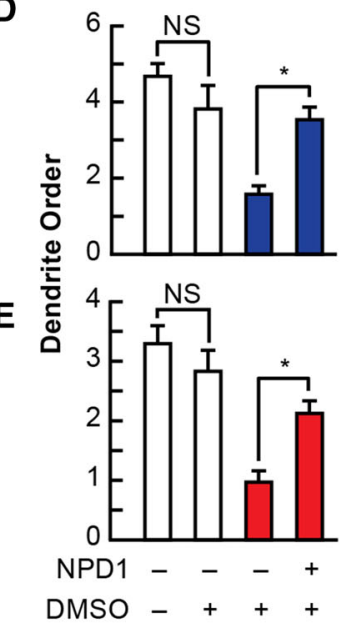

$\mathbf{J}$

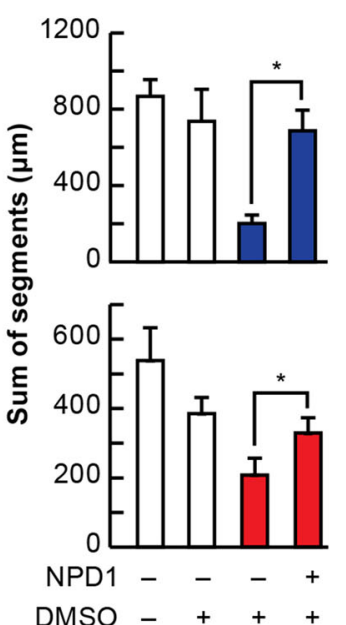

$\mathbf{L}$
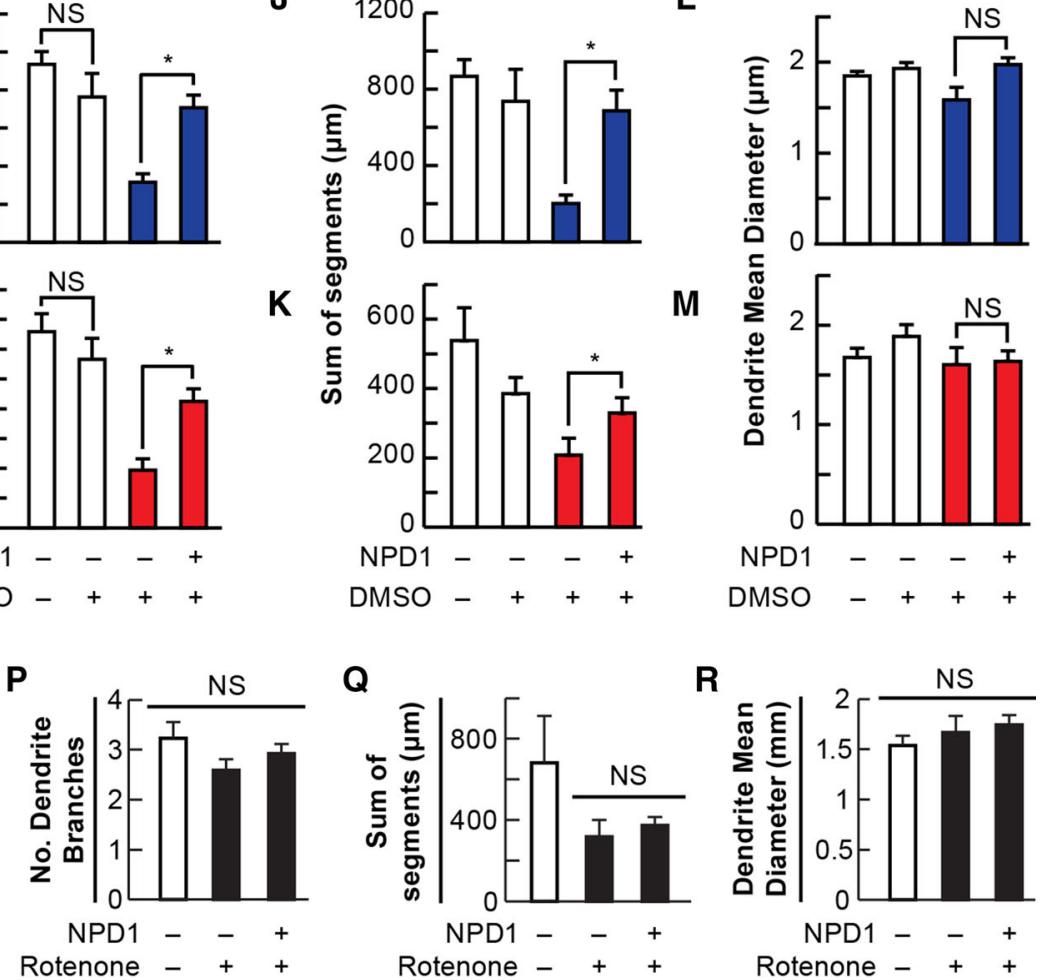

Q

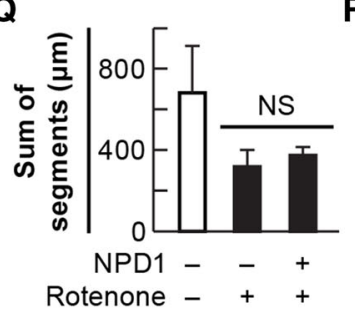

$\mathbf{R}$

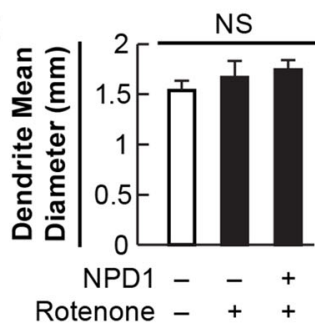

Fig. 1 NPD1 promotes survival and prevents dendrite dystrophy of dopaminergic neurons upon addition of MPTP, MPP + , and rotenone. a-c Neuron survival was measured by a direct count of tyrosine hydroxylase-positive neurons per random field by triplicate per well in at least two wells per condition in two independent experiments. a Representative images of mesencephalic neuronal culture neurons stained with MAP2 (red first column) and tyrosine hydroxylase (green second column); nuclei are blue. b, c Tyrosine hydroxylase-positive cells after 24-h $100 \mu \mathrm{M}$ MPP+ or $100 \mu \mathrm{M}$ MPTP (b) and $100 \mathrm{nM}$ rotenone (c) treatment in the presence or absence of $100 \mathrm{nM}$ NPD1 (b, c) or 10S-17S-diHDHA stereoisomer (c). d-m Neurons that survived MPP+ or MPTP in the presence of NPD1 showed a better dendritic architecture than those that were not treated with NPD1. d, e Maximum dendritic order, $\mathbf{f}, \mathbf{g}$ number of segments, $\mathbf{h}, \mathbf{i}$ number of branches, $\mathbf{j}$, $\mathbf{k}$ sum of the length of all the segments per neuron, and $\mathbf{l}$, $\mathbf{m}$ the mean diameter of the dendrites in MPP+- $(\mathbf{d}, \mathbf{f}, \mathbf{h}, \mathbf{j}, \mathbf{l})$ or MPTP- $(\mathbf{e}, \mathbf{g}, \mathbf{i}, \mathbf{k}, \mathbf{m})$ treated cells in the presence or absence of NPD1. DMSO was added as vehicle control. Isolated TH-positive neurons from three random fields per well in two wells per experiment were traced using IMARIS 7. Two experiments were pooled together. n-r TH-positive neurons that survived $100 \mathrm{nM}$ rotenone treatment for $24 \mathrm{~h}$ : $\mathbf{n}$ maximum dendritic order, $\mathbf{o}$ number of segments, $\mathbf{p}$ number of branches, $\mathbf{q}$ sum of the length of all the segments per neuron, and $\mathbf{r}$ the mean diameter of the dendrites. Total neurons included for $\mathbf{d}, \mathbf{f}, \mathbf{h}, \mathbf{j}, \mathbf{l}$ were control $N=22$, DMSO $N=11$, $\mathrm{MPP}+N=25$, and $\mathrm{MPP}++\mathrm{NPD} 1 N=37$. For $\mathbf{e}, \mathbf{g}, \mathbf{i}, \mathbf{k}, \mathbf{m}$ : control $N=23, \quad$ DMSO $\quad N=16, \quad \mathrm{MPP}+N=17 \quad$ and $\mathrm{MPP}++\mathrm{NPD} 1 N=30$. For $\mathbf{n}-\mathbf{r}$, control $N=10$, rotenone + , rotenone $+\operatorname{NPD} 1 N=33$, and rotenone alone $N=18$. Bars represent the mean \pm SEM. $* P<0.05, N S$ non-significant $P$ value 


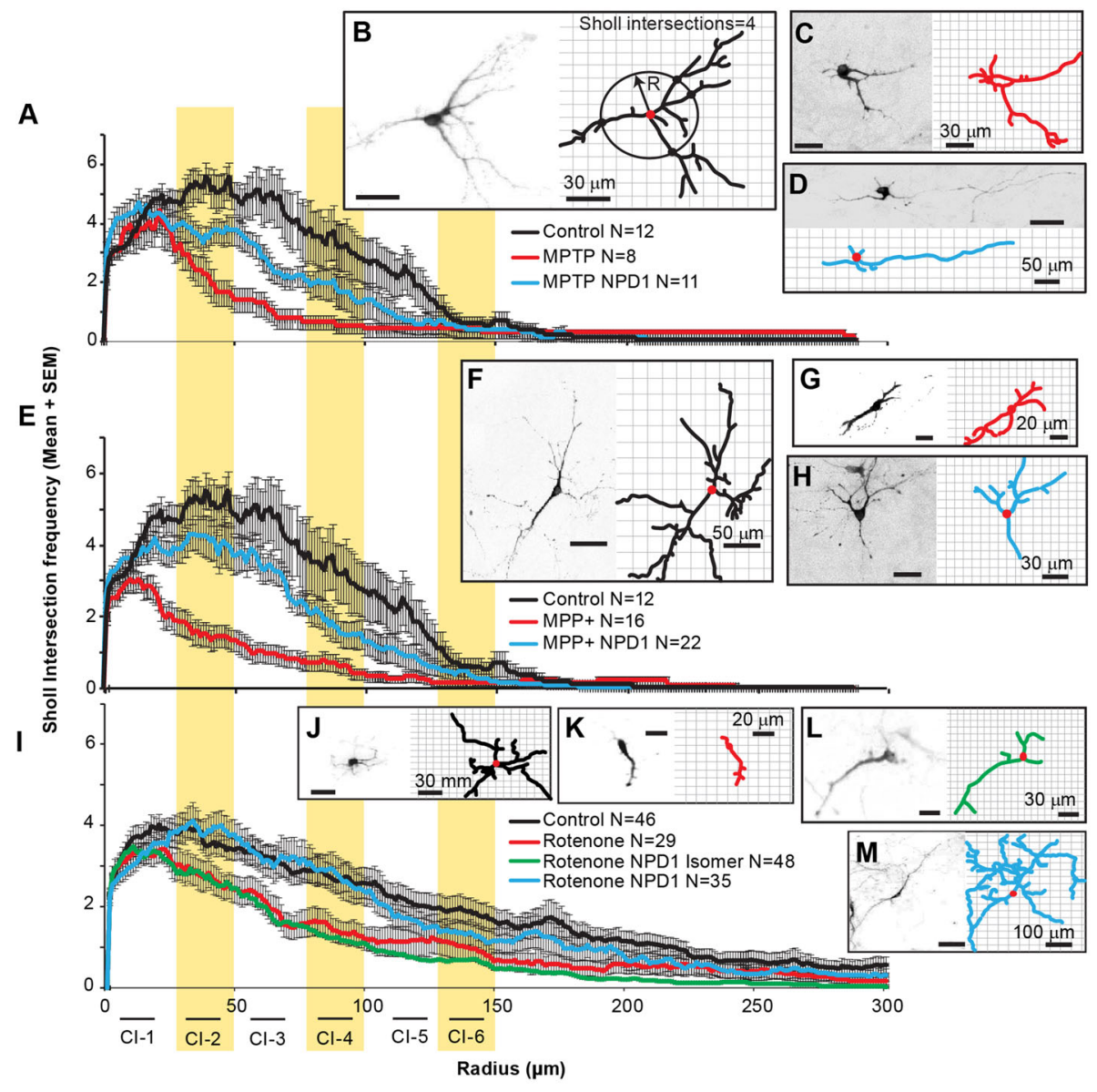

$\mathbf{N}$

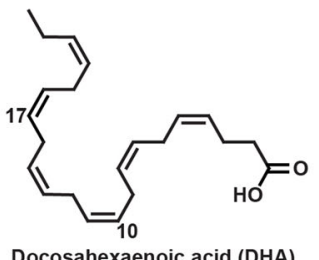

0

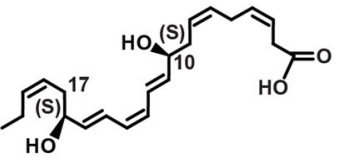

10S,17S-diHDHA

double dioxygenation product
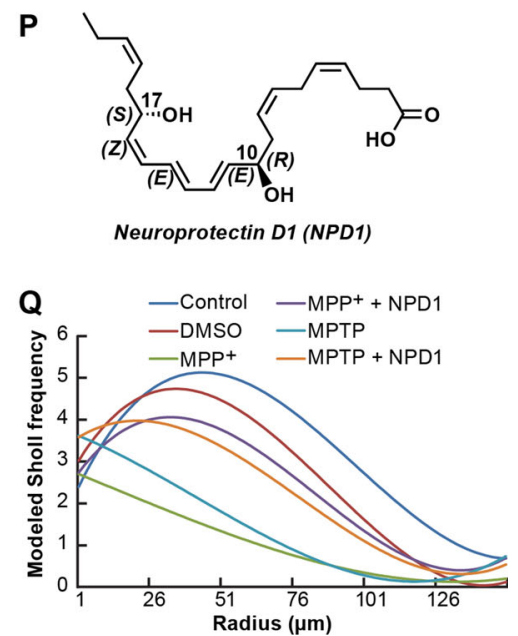

Fig. 2 NPD1 prevents disruption of dendritic architecture caused by MPP+, MPTP, or rotenone. The dendritic architecture was assessed using Sholl analysis, which involves calculating the frequency at which the dendritic arbor intersects a series of concentric circles separated by $1 \mu \mathrm{m}$ using the soma as the center (b right panel). a, e Sholl number of intersections (averaged) versus radius of neurons treated with a MPTP, e MPP+ and $\mathbf{i}$ rotenone in the presence or absence of NPD1. In all cases, comparisons were made against nontreated neurons (control). The curves were fitted to a polynomial regression model using a least squares regression model $(P<0.0001)$; see Supplementary Tables $1-5$ and Supplementary

control cells, a lesser proportion of primary neurites was terminal (Fig. 3c, d). Consistent with the effect of the terminal segments that induced their retraction, the order at which the curve peaked was lower with MPP+, so this was the order at which the values became zero; this means the most abundant terminal neurites were located at order 2 , and there were no dendrites at order 6. Once again, NPD1treated neurons presented dendritic arbor architecture similar in configuration to that of the vehicle, as well as a preserved maximum distal dendrite order.

Altogether, these results suggest that the damage caused by MPP+ induces a diminished arborization, which is a product of terminal neurite retraction. The addition of
Fig. 4. b-d, f-m Right and left panels show a neuron and its corresponding tracings as an output of the IMARIS software, respectively. b, f, j Control neurons or treated with $\mathbf{c}, \mathbf{d} 100 \mu \mathrm{m}$ MPTP; $\mathbf{g}, \mathbf{h} 100 \mu \mathrm{m}$ MPP+; $\mathbf{k}-\mathbf{m}$ rotenone $100 \mathrm{nM} ; \mathbf{d}, \mathbf{h}, \mathbf{m}$ plus of NPD1 or $\mathbf{l}$ its $S-S$ stereoisomer. The values are represented as the mean \pm SEM. $N S$ non-significant $P$ value. $\mathbf{n}, \mathbf{o}$ Molecular structure of n DHA; o 10S-17S-diHDHAstereoisomer and p NPD1. q Polynomial regression model for MPP+ and MPTP Sholl intersections. The mathematical formulas for the curves plotted are described in Supplementary Table 1. Isomer: 10S,17S-diHDHA

NPD1 reversed the damage produced by MPP + , bringing the number of dendrites back to the levels of vehicletreated neurons.

\section{Discussion}

NPD1 is a docosahexaenoic acid derivative shown to be protective in neurons and RPE cells undergoing proteotoxic and oxidative stress damage (Mukherjee et al. 2004; Calandria et al. 2012) as well as in other dysruptions of homeostasis (Bazan et al. 2011). Here we report specific NPD1 effects on the survival and dendrite architecture of 
Table 1 Sholl intersection number mean under least squares model

\begin{tabular}{|c|c|c|c|c|c|}
\hline Radius $(\mu \mathrm{m})$ & Treatment & $\begin{array}{l}\text { Sholl least squares } \\
\text { mean }\end{array}$ & $\begin{array}{l}\text { Standard error of the least } \\
\text { squares mean }\end{array}$ & $\begin{array}{l}\text { Comparison with the } \\
\text { control }\end{array}$ & $\begin{array}{l}\text { Comparison } \\
\text { between } \pm \text { NPD1 }\end{array}$ \\
\hline \multirow{6}{*}{$\begin{array}{l}0-25 \text { class } \\
\text { interval } 1\end{array}$} & Control & 3.83666667 & 0.07223875 & & \\
\hline & DMSO & 4.24888889 & 0.07223875 & 0.0263 & \\
\hline & $\mathrm{MPP}^{+}$ & 2.61000000 & 0.07223875 & $<0.0001$ & $<0.0001$ \\
\hline & $\mathrm{MPP}^{+}+\mathrm{NPD} 1$ & 3.61272727 & 0.07223875 & 0.9678 & \\
\hline & MPTP & 3.59000000 & 0.07223875 & 0.8977 & 0.0003 \\
\hline & MPTP + NPD1 & 4.10909091 & 0.07223875 & 0.7397 & \\
\hline \multirow{6}{*}{$\begin{array}{c}26-50 \text { class } \\
\text { interval } 2\end{array}$} & Control & 5.06333333 & 0.07223875 & & \\
\hline & DMSO & 4.35111111 & 0.07223875 & $<0.0001$ & \\
\hline & $\mathrm{MPP}^{+}$ & 1.56000000 & 0.07223875 & $<0.0001$ & $<0.0001$ \\
\hline & $\mathrm{MPP}^{+}+\mathrm{NPD} 1$ & 4.02727273 & 0.07223875 & $<0.0001$ & \\
\hline & МРTP & 2.26500000 & 0.07223875 & $<0.0001$ & $<0.0001$ \\
\hline & MPTP + NPD1 & 3.70181818 & 0.07223875 & $<0.0001$ & \\
\hline \multirow{6}{*}{$\begin{array}{c}51-75 \text { class } \\
\text { interval } 3\end{array}$} & Control & 4.62847222 & 0.07372836 & & \\
\hline & DMSO & 4.10666667 & 0.07223875 & 0.0003 & \\
\hline & $\mathrm{MPP}^{+}$ & 0.96000000 & 0.07223875 & $<0.0001$ & $<0.0001$ \\
\hline & $\mathrm{MPP}^{+}+\mathrm{NPD} 1$ & 3.25090909 & 0.07223875 & $<0.0001$ & \\
\hline & МРTP & 1.04000000 & 0.07223875 & $<0.0001$ & $<0.0001$ \\
\hline & MPTP + NPD1 & 2.71636364 & 0.07223875 & $<0.0001$ & \\
\hline \multirow{6}{*}{$\begin{array}{c}76-100 \text { class } \\
\text { interval } 4\end{array}$} & Control & 3.28000000 & 0.07223875 & & \\
\hline & DMSO & 2.45333333 & 0.07223875 & $<0.0001$ & \\
\hline & $\mathrm{MPP}^{+}$ & 0.59000000 & 0.07223875 & $<0.0001$ & $<0.0001$ \\
\hline & $\mathrm{MPP}^{+}+\mathrm{NPD} 1$ & 1.75090909 & 0.07223875 & $<0.0001$ & \\
\hline & MPTP & 0.55000000 & 0.07223875 & $<0.0001$ & $<0.0001$ \\
\hline & MPTP + NPD1 & 1.69818182 & 0.07223875 & $<0.0001$ & \\
\hline \multirow{6}{*}{$\begin{array}{l}100-125 \text { class } \\
\text { interval } 5\end{array}$} & Control & 2.19333333 & 0.07223875 & & \\
\hline & DMSO & 0.92444444 & 0.07223875 & $<0.0001$ & \\
\hline & $\mathrm{MPP}^{+}$ & 0.27000000 & 0.07223875 & $<0.0001$ & $<0.0001$ \\
\hline & $\mathrm{MPP}^{+}+\mathrm{NPD} 1$ & 0.94363636 & 0.07223875 & $<0.0001$ & \\
\hline & MPTP & 0.37500000 & 0.07223875 & $<0.0001$ & 0.0129 \\
\hline & MPTP + NPD1 & 0.80727273 & 0.07223875 & $<0.0001$ & \\
\hline \multirow{6}{*}{$\begin{array}{l}126-150 \text { class } \\
\text { interval } 6\end{array}$} & Control & 0.73333333 & 0.07223875 & & \\
\hline & DMSO & 0.21333333 & 0.07223875 & 0.0003 & \\
\hline & $\mathrm{MPP}^{+}$ & 0.12500000 & 0.07223875 & $<0.0001$ & 0.9284 \\
\hline & $\mathrm{MPP}^{+}+\mathrm{NPD} 1$ & 0.36363636 & 0.07223875 & $<0.0001$ & \\
\hline & МРTP & 0.34500000 & 0.07223875 & $<0.0001$ & 1.000 \\
\hline & MPTP + NPD1 & 0.44727273 & 0.07223875 & $<0.0001$ & \\
\hline
\end{tabular}

Mesencephalic neurons were treated with MPTP and MPP+ in the presence or absence of NPD1. The Sholl intersections numbers are shown for TH-positive neurons that survived the 24-h treatment. Data were broken down into 6 class intervals of $25-\mu \mathrm{m}$ radius (left column) and the mean and standard error of the mean were fitted to the least squares regression model (columns 3,4). The Scholl least squares mean values were compared pairwise against the control (column 5) and between samples in the presence or absence of NPD1 (column 6)

TH-positive cells exposed to MPTP, its metabolite MPP+, or rotenone. NPD1 increased the survival of TH-positive cells treated with MPP+ (Fig. 1b) or rotenone (Fig. 1c). MPTP treatment did not reduce the neuron population to the same extent, and NPD1-mediated neuroprotection was not as strong as with the other two toxins (Fig. 1b).
Interestingly, MPTP toxicity was not reversed by NPD1 to the same extent as MPP + , suggesting that both actions are executed by different mechanisms. MPTP conversion to MPP + and release occurs in glial cells (Ransom et al. 1987). It may be possible that this processing of MPTP delays and decreases the amount of MPP + that reaches 
Table 2 Sholl intersection number mean under least squares model

\begin{tabular}{|c|c|c|c|c|c|c|}
\hline Radius $(\mu \mathrm{m})$ & Treatment & $\begin{array}{l}\text { Sholl } \\
\text { mean }\end{array}$ & $\begin{array}{l}\text { Standard error of } \\
\text { the mean }\end{array}$ & $\begin{array}{l}\text { Sholl least } \\
\text { squares mean }\end{array}$ & $\begin{array}{l}\text { Standard error of the least } \\
\text { squares mean }\end{array}$ & $\begin{array}{l}\text { Comparison with } \\
\text { control }\end{array}$ \\
\hline \multirow{4}{*}{$\begin{array}{l}0-25 \text { class } \\
\text { Interval } 1\end{array}$} & Control & 3.566087 & 0.050271 & 3.56608696 & 0.05458508 & \\
\hline & Rotenone + NPD1 & 3.053846 & 0.051608 & 3.17600000 & 0.06257759 & 0.0006 \\
\hline & Rotenone & 3.176552 & 0.054958 & 3.17655172 & 0.06874702 & 0.0021 \\
\hline & Rotenone + isomer & 3.069712 & 0.04671 & 3.24434783 & 0.05458508 & 0.0061 \\
\hline \multirow{4}{*}{$\begin{array}{c}26-50 \text { class } \\
\text { Interval } 2\end{array}$} & Control & 3.655652 & 0.048947 & 3.65565217 & 0.05458508 & \\
\hline & Rotenone + NPD1 & 3.889143 & 0.07469 & 3.88914286 & 0.06257759 & 0.4237 \\
\hline & Rotenone & 2.732414 & 0.07011 & 2.73241379 & 0.06874702 & $<0.0001$ \\
\hline & Rotenone + isomer & 2.709135 & 0.053452 & 2.74869565 & 0.05458508 & $<0.0001$ \\
\hline \multirow{4}{*}{$\begin{array}{c}51-75 \text { class } \\
\text { Interval } 3\end{array}$} & Control & 3.153043 & 0.059304 & 3.15304348 & 0.05458508 & \\
\hline & Rotenone + NPD1 & 3.245714 & 0.08262 & 3.24571429 & 0.06257759 & 1.0000 \\
\hline & Rotenone & 1.964138 & 0.066669 & 1.96413793 & 0.06874702 & $<0.0001$ \\
\hline & Rotenone + isomer & 1.860833 & 0.050282 & 1.89130435 & 0.05458508 & $<0.0001$ \\
\hline \multirow{4}{*}{$\begin{array}{l}\text { 76-100 class } \\
\text { Interval } 4\end{array}$} & Control & 2.726957 & 0.066676 & 2.72695652 & 0.05458508 & \\
\hline & Rotenone + NPD1 & 2.745143 & 0.080876 & 2.74514286 & 0.06257759 & 1.0000 \\
\hline & Rotenone & 1.445517 & 0.060717 & 1.44551724 & 0.06874702 & $<0.0001$ \\
\hline & Rotenone + isomer & 1.236667 & 0.049299 & 1.25739130 & 0.05458508 & $<0.0001$ \\
\hline \multirow{4}{*}{$\begin{array}{l}\text { 100-125 class } \\
\text { Interval } 5\end{array}$} & Control & 2.222609 & 0.066566 & 2.22260870 & 0.05458508 & \\
\hline & Rotenone + NPD1 & 1.816 & 0.058925 & 1.81600000 & 0.06257759 & $<0.0001$ \\
\hline & Rotenone & 1.157241 & 0.071509 & 1.15724138 & 0.06874702 & $<0.0001$ \\
\hline & Rotenone + isomer & 0.814167 & 0.038327 & 0.82782609 & 0.05458508 & $<0.0001$ \\
\hline \multirow{4}{*}{$\begin{array}{l}\text { 126-150 class } \\
\text { Interval } 6\end{array}$} & Control & 1.848696 & 0.064044 & 1.84869565 & 0.05458508 & \\
\hline & Rotenone + NPD1 & 1.313143 & 0.057406 & 1.31314286 & 0.06257759 & $<0.0001$ \\
\hline & Rotenone & 0.982069 & 0.06284 & 0.98206897 & 0.06874702 & $<0.0001$ \\
\hline & Rotenone + isomer & 0.648333 & 0.034167 & 0.66173913 & 0.05458508 & $<0.0001$ \\
\hline
\end{tabular}

Mesencephalic neurons were treated with $100 \mathrm{nM}$ rotenone in the presence or absence of NPD1. The Sholl intersections numbers are shown for TH-positive neurons that survived the 24-h treatment. Data were broken down into 6 class intervals of 25 - $\mu$ m radius (left column) and the mean and standard error of the mean (columns 3,4 ) were fitted to the least squares regression model (columns 5,6). The Sholl least squares mean values were compared pairwise against the control (column 7). Isomer: 10S,17S-diHDHA

neurons, thus causing a weaker but sustained damage compared to the acute insult produced by MPP+. This may explain the differences in TH-positive neurons survival and the protection exerted by NPD1 (Fig. 1b).

Here we report an $81 \%$ disappearance of TH-positive neurons (from $40.3 \pm 7.3$ in the control to $7.6 \pm 1.6$ in $\mathrm{MPP}+$-treated neurons). MPP + selectively damages cells expressing DAT (Holzschuh et al. 2001), and at least $81 \%$ of the TH-positive cells (17-20\% of the total neuronal population) are dopaminergic neurons. Consequently, the majority of cells rescued from death by NPD1 were also dopaminergic. We cannot discount, however, the presence of other catecholaminergic cells. In fact, damage in the noradrenergic system increases dopaminergic neurotoxicity in MPTP-treated primate and MPTP-treated rodent animal models (Fornai et al. 1997); however, there is no clear evidence that non-dopaminergic neurons in culture reacts to $\mathrm{MPP}+$.
DHA decreases caspase-dependent actin cleavage at dendrites when neurons undergo oxidative stress (Calon et al. 2004). Also, under oxidative stress conditions, DHA is converted into NPD1 (Calandria et al. 2009) and the latter decreases caspase activation in neurons (Calandria et al. 2012; Mukherjee et al. 2004).

The neurons surviving MPTP or MPP+ treatments showed, on average, a decrease in dendrite order and number of dendritic segments, as well as reduced branching (Fig. 1d-k). Rotenone affected the dendritic order and number of segments (Fig. 1n, o, q) but did not affect the number of branches (Fig. 1p). Accordingly, the extent and pattern of the damage displayed in the assessment of Sholl intersections differed significantly from MPTP/MPP + and rotenone, suggesting specific mechanisms of action for both types of toxins.

$\mathrm{MPP}+$, a metabolite of MPTP, induces damage in SNpc dopaminergic neurons. Although it is not known why this 
Fig. 3 Terminal dendrites are preserved with NPD1 treatment. TH-positive neurons were traced using a NeuronJ plug-in of ImageJ. a, c Average of the dendritic order. $\mathbf{b}, \mathbf{d}$ Average of segments for each dendritic order $(\mathbf{a}, \mathbf{b})$ and terminal dendrites (c, d) in control, DMSO- or MPP+-treated cells, the latter in the presence or absence of NPD1. The values are represented as the mean \pm SEM. $* P<0.05$. NS non-significant $P$ value
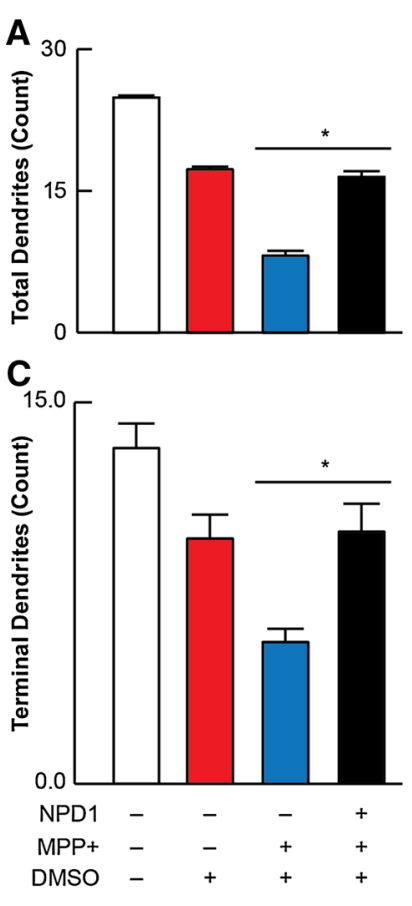

metabolite prefers SNpc neurons specifically, it was proposed that MPP+ is internalized by neurons through the dopamine transporter DAT and that it may induce oxidation of intracellular dopamine, which confers dopaminergic neuronal specificity to the toxin (Holzschuh et al. 2001). It was proposed that MPP+ inhibits mitochondrial Complex I, enhancing the production of reactive oxygen species (ROS) (Cleeter et al. 1992) and inducing a mild depletion in ATP (Chan et al. 1991), features observed in PD postmortem brains (Parker et al. 1989; Schapira et al. 1990; Keeney et al. 2006).

Other lines of evidence contradict the Complex I hypothesis. For instance, midbrain mesencephalic-cultured dopaminergic neurons that lack Ndufs4, a key assembly subunit in Complex I and thus a functional Complex I, have survived and shown normal morphology (Choi et al. 2008). These neurons displayed more sensitivity to rotenone and $\mathrm{MPP}+$ than the Ndufs $4+/+$ dopaminergic neurons. Following this line of thought, it was recently proposed that microtubule dysfunction may be the mechanism responsible for the rotenone effect on dopaminergic cells, and the lack of functional Complex I may potentiate this toxicity (Choi et al. 2011). It also was shown that MPP+ (Cappelletti et al. 2005; Cartelli et al. 2010) and rotenone (Choi et al. 2011) have an effect on the cytoskeleton that may provide an explanation for the shrinkage of the dendritic tree. Since microtubular dysfunction affects neuronal survival in different ways, it

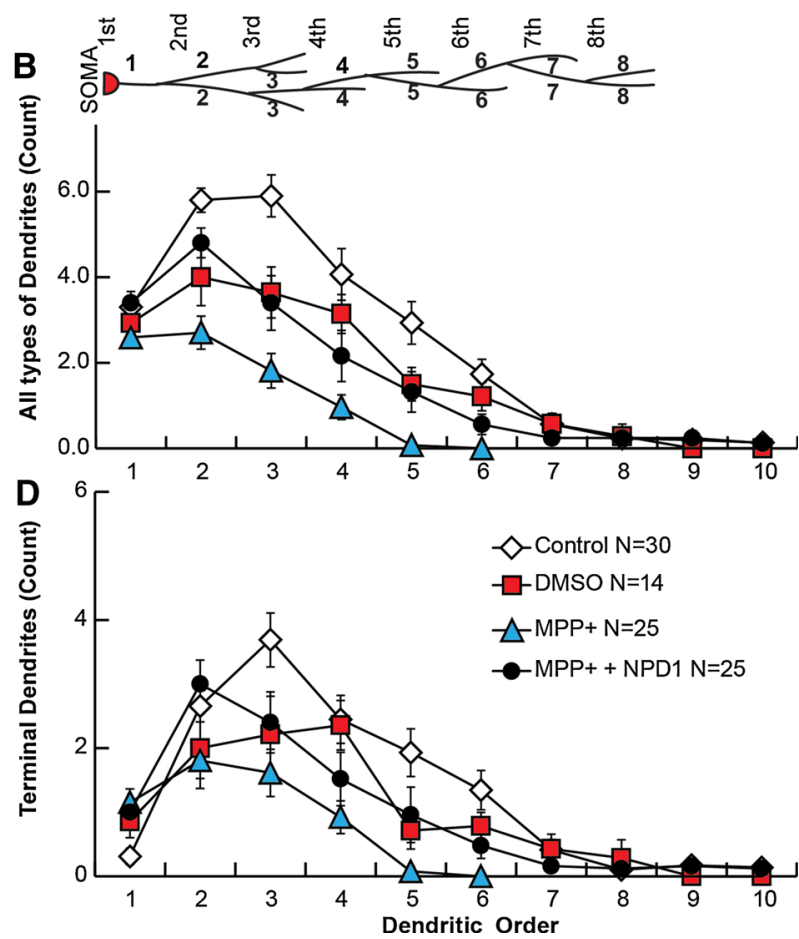

may be an early indicator of neurodegeneration. For instance, autophagy, a microtubular-dependent mechanism during stress conditions (Mackeh et al. 2013), clears damaged mitochondria to prevent toxicity. This process is called mitophagy and is regulated by PINK (Ashrafi and Schwarz 2013), involved in hereditary PD (Valente et al. 2004). Furthermore, autophagy was found to be compromised in conditional ATG7 knockout mice, with a subsequent decrease of dopaminergic neurons in the SNpc and an accumulation of $\alpha$-synuclein and LRRK2 (Friedman et al. 2012). Our results indicate that terminal dendrites are compromised in MPP+-surviving TH-positive neurons (Fig. 3). Dendritic dystrophy, a reduction in length and complexity of dendrites, is a common feature of neurodegeneration, most often observed in PD (Friedman et al. 2012). Although in our cellular model, no morphological signals of initial dendrotoxicity, such as neurite beading, were observed after $24 \mathrm{~h}$ of treatment, the disappearance of terminal segments (Figs. 1d-g, j-k, n-o, q, 3) and diminished branching occurred (Figs. 1h-i, 2a, e, i) in response to MPTP, MPP+ and rotenone. In the Drosophila's larval multidendritic neuron model, dendrite degeneration is an active programmed process that can take place within the first $24 \mathrm{~h}$ of toxic exposure (Tao and Rolls 2011). This timing may explain the absence of dendritic beading observed.

Protein phosphate 2A (PP2A) is a master regulator of the phosphorylation/dephosphorylation processes, including 
microtubule stabilization/destabilization. Recently, NPD1 modulates PP2A activity (Antony et al. 2010; Calandria et al. 2012). Furthermore, PP2A was involved in the microtubular dysfunction related to tauopathies present in Alzheimer's disease (Sontag et al. 2012) and also found in postmortem PD brains (Wills et al. 2010). Therefore, the pro-survival activity of NPD1 also may be preventing dendrite retraction.

Taken together, our results suggest that NPD1 promotes survival and preservation of the dendritic tree in dopaminergic neurons undergoing MPP+ or rotenone toxicity by preventing microtubular dysfunction and oxidative stressdriven cell death. The mechanisms by which NPD1 counteracted TH-positive apoptosis and dendrite dystrophy triggered by MPP + and rotenone may involve the activation of PP2A and the inhibition of effector caspases. These findings lay the groundwork for understanding how NPD1 signaling may be manipulated to improve the survival of SNpc dopaminergic cells in preclinical stages of PD and to prevent the progression of neurodegeneration. In future studies, efforts will be made to identify the therapeutic targets using this information. In this way, it may be possible to promote NPD1 signaling at early stages in at-risk populations to reduce the incidence, delay the onset, or lessen the severity of the symptoms later in life by preventing_at least to some extent-dopaminergic cells from dying.

Acknowledgments This work was supported by National Institutes of Health (NIH) Grant P30 GM103340 and the Tucker Couvillion III Memorial Fund in Parkinson's Disease Research from the Almar Foundation. We would like to thank Dr. Hillary Thompson for his statistical support in the analysis of Sholl data.

Compliance with Ethical Standards All experiments involving animals were handled following the protocols on animal experimentation approved by the Institutional Animal Care and Use Committee (IACUC), Louisiana State University Health Sciences Center (LSUHSC), New Orleans. No human participants were involved in the research reported here, therefore informed consent was not required.

Conflict of interest The authors declare that they have no competing interests.

Open Access This article is distributed under the terms of the Creative Commons Attribution 4.0 International License (http:// creativecommons.org/licenses/by/4.0/), which permits unrestricted use, distribution, and reproduction in any medium, provided you give appropriate credit to the original author(s) and the source, provide a link to the Creative Commons license, and indicate if changes were made.

\section{References}

Antony R, Lukiw WJ, Bazan NG (2010) Neuroprotectin D1 induces dephosphorylation of Bcl-xL in a PP2A-dependent manner during oxidative stress and promotes retinal pigment epithelial cell survival. J Biol Chem 285:18301-18308

Ashrafi G, Schwarz TL (2013) The pathways of mitophagy for quality control and clearance of mitochondria. Cell Death Differ $20: 31-42$

Bazan NG (2014) Is there a molecular logic that sustains neuronal functional integrity and survival? Lipid signaling is necessary for neuroprotective neuronal transcriptional programs. Mol Neurobiol 50:1-5

Bazan NG, Calandria JM, Serhan CN (2010) Rescue and repair during photoreceptor cell renewal mediated by docosahexaenoic acidderived neuroprotectin D1. J Lipid Res 51:2018-2031

Bazan NG, Molina MF, Gordon WC (2011) Docosahexaenoic acid signalolipidomics in nutrition: significance in aging, neuroinflammation, macular degeneration, Alzheimer's, and other neurodegenerative diseases. Annu Rev Nutr 31:321-351

Betarbet R, Sherer TB, MacKenzie G, Garcia-Osuna M, Panov AV, Greenamyre JT (2000) Chronic systemic pesticide exposure reproduces features of Parkinson's disease. Nat Neurosci 3:1301-1306

Betarbet R, Sherer TB, Greenamyre JT (2002) Animal models of Parkinson's disease. BioEssays 24:308-318

Calandria JM, Marcheselli VL, Mukherjee PK, Uddin J, Winkler JW, Petasis NA, Bazan NG (2009) Selective survival rescue in 15-lipoxygenase-1 deficient retinal pigment epithelial cells by the novel docosahexaenoic acid-derived mediator, neuroprotectin D1. J Biol Chem 284:17877-17882

Calandria JM, Mukherjee PK, de Rivero Vaccari JC, Zhu M, Petasis NA, Bazan NG (2012) Ataxin-1 poly(Q)-induced proteotoxic stress and apoptosis are attenuated in neural cells by docosahexaenoic acid-derived neuroprotectin D1. J Biol Chem 287:23726-23739

Calandria JM, Asatryan A, Balaszczuk V, Knott EJ, Jun BK, Mukherjee PK, Belayev L, Bazan NG (2015) NPD1-mediated stereoselective regulation of BIRC3 expression through cREL is decisive for neural cell survival. Cell Death Differ. doi:10.1038/ cdd.2014.233

Calon F, Lim GP, Yang F, Morihara T, Teter B, Ubeda O, Rostaing P, Triller A, Salem N Jr, Ashe KH, Frautschy SA, Cole GM (2004) Docosahexaenoic acid protects from dendritic pathology in an Alzheimer's disease mouse model. Neuron 43:633-645

Cappelletti G, Surrey T, Maci R (2005) The parkinsonism producing neurotoxin MPP + affects microtubule dynamics by acting as a destabilising factor. FEBS Lett 579:4781-4786

Cartelli D, Ronchi C, Maggioni MG, Rodighiero S, Giavini E, Cappelletti G (2010) Microtubule dysfunction precedes transport impairment and mitochondria damage in MPP+-induced neurodegeneration. J Neurochem 115:247-258

Chan P, DeLanney LE, Irwin I, Langston JW, Di Monte D (1991) Rapid ATP loss caused by 1-methyl-4-phenyl-1,2,3,6-tetrahydropyridine in mouse brain. J Neurochem 57:348-351

Cherra SJ 3rd, Steer E, Gusdon AM, Kiselyov K, Chu CT (2013) Mutant LRRK2 elicits calcium imbalance and depletion of dendritic mitochondria in neurons. Am J Pathol 182:474-484

Choi WS, Kruse SE, Palmiter RD, Xia Z (2008) Mitochondrial complex I inhibition is not required for dopaminergic neuron death induced by rotenone, MPP+, or paraquat. Proc Natl Acad Sci USA 105:15136-15141

Choi WS, Palmiter RD, Xia Z (2011) Loss of mitochondrial complex I activity potentiates dopamine neuron death induced by microtubule dysfunction in a Parkinson's disease model. J Cell Biol 192:873-882

Cleeter MW, Cooper JM, Schapira AH (1992) Irreversible inhibition of mitochondrial complex I by 1-methyl-4-phenylpyridinium: evidence for free radical involvement. J Neurochem 58:786-789 
Davis GC, Williams AC, Markey SP, Ebert MH, Caine ED, Reichert CM, Kopin IJ (1979) Chronic parkinsonism secondary to intravenous injections of meperidine analogues. Psychiatry Res $1: 249-254$

Fornai F, Alessandri MG, Torracca MT, Bassi L, Corsini GU (1997) Effects of noradrenergic lesions on MPTP/MPP1 kinetics and MPTP-induced nigrostriatal dopamine depletions. J Pharmacol Exp Ther 283:100-107

Friedman LG, Lachenmayer ML, Wang J, He L, Poulose SM, Komatsu M, Holstein GR, Yue Z (2012) Disrupted autophagy leads to dopaminergic axon and dendrite degeneration and promotes presynaptic accumulation of $\alpha$-synuclein and LRRK2 in the brain. J Neurosci 32:7585-7593

Holzschuh J, Ryu S, Aberger F, Driever W (2001) Dopamine transporter expression distinguishes dopaminergic neurons from other catecholaminergic neurons in the developing zebrafish embryo. Mech Dev 101:237-243

Keeney PM, Xie J, Capaldi RA, Bennett JP Jr (2006) Parkinson's disease brain mitochondrial complex I has oxidatively damaged subunits and is functionally impaired and misassembled. J Neurosci 26:5256-5264

Langston JW, Ballard P, Tetrud JW, Irwin I (1983) Chronic Parkinsonism in humans due to a product of meperidine-analog synthesis. Science 219:979-980

Mackeh R, Perdiz D, Lorin S, Codogno P, Poüs C (2013) Autophagy and microtubules-new story, old players. J Cell Sci 126:1071-1080

Meijering E, Jacob M, Sarria JC, Steiner P, Hirling H, Unser M (2004) Design and validation of a tool for neurite tracing and analysis in fluorescence microscopy images. Cytometry A 58:167-176

Mukherjee PK, Marcheselli VL, Serhan CN, Bazan NG (2004) Neuroprotectin D1: a docosahexaenoic acid-derived docosatriene protects human retinal pigment epithelial cells from oxidative stress. Proc Natl Acad Sci USA 101:8491-8496

Parker WD Jr, Boyson SJ, Parks JK (1989) Abnormalities of the electron transport chain in idiopathic Parkinson's disease. Ann Neurol 26:719-723

Ramachandiran S, Hansen JM, Jones DP, Richardson JR, Miller GW (2007) Divergent mechanisms of paraquat, MPP+, and rotenone toxicity: oxidation of thioredoxin and caspase-3 activation. Toxicol Sci 95:163-171
Ransom BR, Kunis DM, Irwin I, Langston JW (1987) Astrocytes convert the parkinsonism inducing neurotoxin, MPTP, to its active metabolite, MPP +. Neurosci Lett 75:323-328

Rasband WS (1997-2014) ImageJ. U.S. National Institutes of Health, Bethesda, MD. http://imagej.nih.gov/ij/

Rice DS, Calandria JM, Gordon WC, Jun B, Zhou Y, Gelfman CM, Li S, Jin M, Knott EJ, Chang B, Abuin A, Issa T, Potter D, Platt KA, Bazan NG (2015) Adiponectin receptor 1 conserves docosahexaenoic acid and promotes photoreceptor cell survival. Nat Commun 6:6228

Richardson JR, Quan Y, Sherer TB, Greenamyre JT, Miller GW (2005) Paraquat neurotoxicity is distinct from that of MPTP and rotenone. Toxicol Sci 88:193-201

Schapira AH, Cooper JM, Dexter D, Clark JB, Jenner P, Marsden CD (1990) Mitochondrial complex I deficiency in Parkinson's disease. J Neurochem 54:823-827

Serhan CN, Dalli J, Colas RA, Winkler JW, Chiang N (2015) Protectins and maresins: new pro-resolving families of mediators in acute inflammation and resolution bioactive metabolome. Biochim Biophys Acta 1851:397-413

Sontag JM, Nunbhakdi-Craig V, White CL 3rd, Halpain S, Sontag E (2012) The protein phosphatase PP2A/B $\alpha$ binds to the microtubule-associated proteins Tau and MAP2 at a motif also recognized by the kinase Fyn: implications for tauopathies. J Biol Chem 287:14984-14993

Sun ZH, Lai YL, Li P, Zuo HC, Xie ZP (2004) GDNF augments survival and differentiation of TH-positive neurons in neural progenitor cells. Cell Biol Int 28:323-325

Tao J, Rolls MM (2011) Dendrites have a rapid program of injuryinduced degeneration that is molecularly distinct from developmental pruning. J Neurosci 31:5398-5405

Valente EM, Abou-Sleiman PM, Caputo V, Muqit MM, Harvey K, Gispert S, Ali Z, Del Turco D, Bentivoglio AR, Healy DG, Albanese A, Nussbaum R, González-Maldonado R, Deller T, Salvi S, Cortelli P, Gilks WP, Latchman DS, Harvey RJ, Dallapiccola B, Auburger G, Wood NW (2004) Hereditary earlyonset Parkinson's disease caused by mutations in PINK1. Science 304:1158-1160

Wills J, Jones J, Haggerty T, Duka V, Joyce JN, Sidhu A (2010) Elevated tauopathy and alpha-synuclein pathology in postmortem Parkinson's disease brains with and without dementia. Exp Neurol 225:210-218 